\title{
A Expectativa do Professor e o Desempenho dos Alunos
}

\author{
Tufi Machado Soares ${ }^{1}$ \\ Neimar da Silva Fernandes \\ Mariana Santos Botarro Ferraz \\ Universidade Federal de Juiz de Fora \\ Juliana de Lucena Ruas de Riani \\ Secretaria de Estado de Educação de Minas Gerais
}

\begin{abstract}
Resumo - Este trabalho enfoca dois aspectos fundamentais na interação professor-aluno: a sintonia entre o professor e sua turma, e a expectativa do professor quanto ao desempenho dos alunos. Cruzando-se informações de diferentes instrumentos contextuais, aplicados aos professores e alunos, com os resultados dos testes cognitivos dos alunos, pôde-se identificar os fatores que distorcem a percepção do professor acerca da turma e influenciam sua expectativa. Constatou-se que a expectativa do professor é influenciada por suas percepções em relação ao ambiente escolar e pelas características sociodemográficas dos alunos. Observou-se que a expectativa do professor provoca um impacto positivo na proficiência do aluno, mesmo considerandose o efeito de variáveis sociodemográficas tradicionalmente associadas ao desempenho. Essas conclusões foram obtidas a partir da construção de modelos hierárquicos.
\end{abstract}

Palavras-chave: avaliação educacional; expectativa do professor; desempenho do aluno; modelos de regressão hierárquicos.

\section{Teacher's Expectation and Students' Performance}

\begin{abstract}
This work focus on two basic aspects on teacher-student interaction: the tune between teacher and their class, and teacher's expectation with regard to students' performance. When cross analyzing the information of different contextual instruments, applied to teachers and students, with results of the students' cognitive tests, it was possible to identify the factors that distort the teacher's perception about the class and influence his/her expectation. It was noticed that the teacher's expectation is influenced by his/her perceptions in relation to the school environment and the students' social-demographic characteristics. It was observed that the teacher's expectation provokes a positive impact on the student's proficiency, even when it is considered the effect of social-demographic variables, which are traditionally associated to the performance. All these conclusions were obtained by constructing hierarchical models.
\end{abstract}

Keywords: educational evaluation; teacher's expectation; student's performance; hierarchical linear modeling.

As “Avaliações em Larga Escala” são um dos elementos importantes na busca de soluções para se garantir o acesso dos alunos a um ensino de qualidade nas diferentes redes de ensino. O Ministério da Educação, por meio do Sistema de Avaliação da Educação Básica (SAEB), avalia a qualidade nacional do ensino a cada dois anos. Alguns estados como Rio de Janeiro, Minas Gerais, São Paulo, Rio Grande do Sul e Ceará, entre outros, possuem programas específicos como o Sistema de Avaliação do Rendimento Escolar do Estado de São Paulo (SARESP) e o Sistema Mineiro de Avaliação da Educação Pública (SIMAVE), de onde são extraídos os dados usados nesta pesquisa. Para uma discussão mais abrangente das finalidades, objetivos e demais características das Avaliações em Larga Escala, pode-se consultar, por exemplo, Bonamino (2002) e Penna Firme (1982).

Os resultados dos alunos que participam das Avaliações em Larga Escala são apresentados segundo uma escala contínua de desempenho, com nível de mensurabilidade intervalar, construídos a partir de modelos psicométricos da

1 Endereço para correspondência: Centro de Políticas Públicas e Avaliação da Educação - CAEd. Universidade Federal de Juiz de Fora - UFJF. Av. Dr. Deusdedith Salgado, 1311 - B, Cascatinha. Juiz de Fora, MG. CEP 36033-000.E-mail: tufi@caed.ufjf.br.
Teoria da Resposta ao Item (TRI) (Lord, 1980), de forma a se poder compará-los com os resultados de outras avaliações. Esse tipo de escala é, genericamente, denominado de escala de proficiências. A utilização da Teoria da Resposta ao Item permite, ainda, a produção de uma escala única para os diversos níveis de aprendizado (cf. Klein, 1997), viabilizando a comparação do desempenho dos alunos de diferentes séries e sistemas educacionais.

Em Minas Gerais, a Secretaria de Estado da Educação instituiu, no ano de 2000, o (SIMAVE), que realiza, anualmente, o Programa de Avaliação da Educação Básica (PROEB). No PROEB, como no SAEB e na maior parte dessas avaliações, os testes são aplicados aos alunos da $4^{\mathrm{a}}$ e $8^{\mathrm{a}}$ séries do Ensino Fundamental e do $3^{\circ}$ ano do Ensino Médio.

Além dos testes, no PROEB são aplicados questionários contextuais específicos. Alunos respondem a um questionário com perguntas relacionadas ao padrão de vida, às características culturais, aos hábitos de estudo, às características familiares, ao apoio familiar e ao ambiente escolar. No questionário dos professores, são apresentadas questões relativas às características sociodemográficas, à formação profissional e a práticas pedagógicas. O questionário do diretor, do mesmo modo, é aplicado para apurar dados referentes às características sociodemográficas, bem como titulação e características 
do exercício profissional, além de uma avaliação geral das condições da escola e do trabalho dos professores.

Todas essas informações são coletadas com o objetivo de explicar as proficiências dos alunos e de encontrar fatores associados à eficácia e à equidade da educação fornecida pelas escolas.

A maior parte dos trabalhos de análises contextuais das Avaliações em Larga Escala tem como propósito explicar a proficiência dos alunos com base em fatores intra e extraescolares. Entretanto, o inter-relacionamento entre tais fatores é colocado em segundo plano, fazendo com que não sejam estudadas as condições que os afetam e, consequentemente, não sejam concebidas estratégias de intervenção a partir desses inter-relacionamentos.

O impacto da expectativa do professor no desempenho do aluno vem sendo estudado na literatura sistematicamente ao longo de, pelo menos, 40 anos. Em um dos trabalhos pioneiros, Rosenthal e Jacobson (1968) realizaram um estudo controlado em uma escola pública nos Estados Unidos, em que alunos foram apontados aos professores como sendo de alto potencial (growth spurters), teoricamente a partir de resultados de testes cognitivos. No entanto, os alunos foram escolhidos aleatoriamente, e sequer fizeram o teste cognitivo apontado pelos pesquisadores. Após um ano, o resultado encontrado foi de que os alunos, apontados aos professores como sendo de alto potencial, acabaram apresentando um crescimento em suas proficiências, em média, $50 \%$ maior que a dos demais. Fica subentendida, no estudo de Rosenthal e Jacobson, a interação entre a expectativa e o desempenho do aluno, com efetiva intervenção do professor no processo de aprendizado.

Por outro lado, Clifford e Walster (1973) realizaram um estudo em que as fotos de um grupo de alunos eram apresentadas a dois grupos de professores: o primeiro julgou a aparência física dos alunos (attractiveness) e o segundo julgou o provável desempenho acadêmico, o relacionamento social e as perspectivas de promoção acadêmica. Os autores mostraram a existência de correlação entre os dois julgamentos. Os autores concluíram que os professores constroem sua expectativa, em parte, pela característica física dos alunos.

Mais recentemente, Alvidrez e Weinstein (1999) estudaram a associação entre a avaliação da inteligência e personalidade, por parte dos professores, de um grupo de 110 alunos na Pré-Escola, com 4 anos de idade, e o desempenho dessas crianças em dois testes realizados no final do Ensino Médio (Scholastic Aptitude Test - SAT e Grade Point Average - GPA). Além da avaliação dos professores, os alunos tiveram, ainda, uma medida de inteligência obtida por um teste objetivo. Crianças com maior condição socioeconômica e percebidas como independentes foram avaliadas como mais inteligentes pelos professores do que foi apontado no teste objetivo. Por outro lado, crianças com menor condição socioeconômica e percebidas como imaturas foram avaliadas como menos inteligentes do que apontado no teste. Após o controle pela condição socioeconômica do aluno, a sub ou superestimação da inteligência relativamente à medida obtida no teste objetivo previram significativamente os resultados no SAT e no GPA.
O presente trabalho tem como objetivo geral estudar a relação da "expectativa" do professor, quanto ao desempenho da sua turma em um subconjunto específico de questões do teste do PROEB - 2006, com o resultado em todo o teste e com variáveis contextuais, como a condição socioeconômica dos alunos, obtidas por meio de questionários aplicados a alunos e professores. Um objetivo adicional é estudar a relação da "sintonia" entre o desempenho e a expectativa, com as variáveis contextuais e o resultado no teste. Esperase que o professor seja capaz de diagnosticar, pelo menos em parte, o desempenho de seus alunos no teste com base no que é ensinado e no conhecimento prévio que ele tem da situação de aprendizado de sua turma. Entretanto, podem ocorrer, em parte, desvios na percepção dos professores, provocando erros nesse diagnóstico. Este trabalho busca mapear quais variáveis podem provocar tais desvios e de que forma influenciam o diagnóstico, tanto aquele que subestima quanto aquele que superestima o desempenho dos alunos. Também procura avaliar o efeito líquido da expectativa sobre a proficiência, após o controle das variáveis que alteram a percepção do professor.

\section{Método}

\section{Participantes}

Este estudo levou em consideração informações de 4.749 escolas de Minas Gerais que participaram do Programa de Avaliação da Educação Básica (PROEB/2006), das quais 2.185 pertenciam à Rede Estadual de ensino e 2.484, à Municipal. Foram utilizados dados obtidos a partir de questionários aplicados a 258.670 alunos da $4^{\mathrm{a}}$ série do Ensino Fundamental, além dos resultados do teste do PROEB..Além das informações prestadas pelos alunos, foram utilizadas informações fornecidas por 11.153 professores em um questionário próprio. As respostas de todos alunos e professores foram incluídas neste estudo.

\section{Instrumentos}

Questionário do professor. Esse questionário continha três partes. A primeira abordava características sociodemográficas, disciplina lecionada e participação em programas de formação continuada.

A segunda parte abordava temas variados como "relacionamento com os colegas e com o diretor", "motivação pessoal", "relação com os pais dos alunos", "indisciplina dos alunos", "disponibilidade de materiais didáticos" e "instalações da escola", entre outros. Para abordar esses temas, solicitou-se ao professor que fornecesse seu nível de concordância com o conteúdo de determinadas expressões associadas. Para cada tema (e.g., relacionamento com os colegas) eram apresentadas algumas assertivas (e.g., O projeto educacional desta escola é consequência da troca de ideias entre os professores), sendo solicitado ao professor que expressasse sua concordância com o conteúdo da asssertiva por 
meio de uma escala Lickert com cinco níveis $(1$ - discordo plenamente; 5 - concordo plenamente).

Na terceira parte do questionário foram inseridas 12 imagens de itens pertencentes aos testes cognitivos do PROEB, para os quais se solicitou aos professores uma estimativa da parcela da turma que acertaria o item, conforme mostra a Figura 1.

Os temas abordados no questionário do professor foram escolhidos a partir de um estudo do referencial teórico utilizado pelos especialistas em educação para explicar o desempenho dos alunos nos testes. As assertivas apresentadas aos professores se relacionavam a um ou a mais temas. Por esse motivo, as respostas manifestadas para as diferentes assertivas apresentadas aos professores não são totalmente independentes. As expressões, em diversos casos, foram, propositalmente, construídas de maneira que estivessem associadas a um tema específico, e também porque determinadas associações poderiam ocorrer.

Questionário do aluno. Esse questionário foi dividido em três partes. Na primeira parte, apresentaram-se questões sociodemográficas, abrangendo cor, gênero e idade. Na segunda, foram abordadas questões acerca da posse de bens, tanto de caráter de conforto, tais como o número de geladeiras e carros na residência, quanto de caráter cultural, tais como número de computadores e livros, e se a família do aluno recebia "Bolsa-Família".

A terceira parte foi constituída por questões que expressavam a vivência escolar sob o enfoque do aluno. Foram incluídas, nessa parte, frases que expressavam fatos associados ao comportamento em sala de aula, ao empenho do professor e seu compromisso com o conteúdo (e.g., "O(A) professor(a) se esforça para ajudar os alunos"). Solicitou-se que o aluno marcasse a opção que refletisse a maior proximidade entre o número de vezes em que os fatos ocorriam em sala de aula e os pontos de uma escala Likert com quatro níveis ordinais. O primeiro nível correspondia ao fato percebido pelo aluno "Em todas as aulas" e o quarto nível, ao fato "Nunca" percebido por ele.

\section{Análise de dados}

O relacionamento entre as respostas atribuídas às assertivas pode ser conceitualmente explicado pela existência de um constructo ou fator latente, não observado diretamente. Para identificar os constructos, ou ainda, confirmar a existência daqueles que foram previamente concebidos, utiliza-se uma série de técnicas estatísticas denominadas, genericamente, de Análise Fatorial.

Na Análise Fatorial, a variância - medida de variabilidade observada para as diferentes respostas de uma assertiva pode ser decomposta em uma parte comum, ou seja, compartilhada com as respostas de outras assertivas, e teoricamente explicada pelos fatores (uma possível representação para o constructo latente), ou em uma parte específica, aquela exclusiva à assertiva, e não explicada pelos fatores (cf. Johnson \& Wichern (1992).

A partir do modelo construído, pode-se: (i) definir o número de fatores necessários para explicar, adequadamente, as correlações observadas para as assertivas e, consequentemente, o grau de explicação obtido com esse modelo; (ii) observar quais as assertivas mais correlacionadas com cada fator. Essas assertivas podem ser utilizadas com o intuito de se interpretar e identificar o fator como a representação para a construção teórica, isto é, para o constructo.

$\mathrm{Na}$ solução do primeiro problema (i), pode-se utilizar certas diretrizes, das quais algumas foram empregadas neste trabalho, como identificar se o percentual da variância explicada pelo modelo com um determinado número de fatores é expressivamente maior que aquela explicada pelo modelo que inclui todos os fatores. Quanto ao segundo problema (ii), este pode ser resolvido pela inspeção das chamadas cargas, que medem a associação entre um fator e cada variável. Variáveis com valores baixos para as cargas são candidatas à eliminação na explicação de um fator determinado, ou, até mesmo, do modelo. Uma solução útil, que facilita a análise e a interpretação dos fatores, é um modelo em que as variáveis apresentam cargas elevadas para um único fator e cargas

\section{Item 5}

(M04032SI) Maria tem 30 chaveiros. Ela agrupou esses chaveiros de $3 \mathrm{em} 3$. Quantos agrupamentos Maria fez?
A) 10
B) 13
C) 33
D) 90

1) Qual é a sua expectativa em relação à parcela de alunos que conseguirão responder a esta questão?

Todos.

$\square$ Mais da metade.

Metade.

Menos da metade.

Uns poucos.

Nenhum.

Figura 1. Exemplo de item apresentado ao professor durante o 'experimento'. 
pouco expressivas para os demais. Para se alcançar uma configuração desse tipo, pode-se utilizar um procedimento muito comum, que consiste na transformação dos fatores originalmente construídos. Esse procedimento é a rotação ortogonal pelo método Varimax.

Os fatores são interpretados levando em consideração a correlação de cada um deles com cada variável: quanto maior a correlação, em valores absolutos, maior será a influência do fator na variável considerada, e o sinal indica se ambos aumentam na mesma direção ou na direção reversa.

Finalmente, a medida do fator, utilizada em análises posteriores, como, por exemplo, na explicação das proficiências dos alunos, foi extraída a partir de um modelo uni ou multidimensional. Na solução multidimensional, o modelo é construído, simultaneamente, com todos os fatores e todas as variáveis. Por outro lado, no caso unidimensional, selecionam-se as assertivas mais correlacionadas com o fator em questão, garantindo-se que a presença somente desse fator explique uma porcentagem expressiva da variância.

A análise fatorial foi empregada na produção de medidas e interpretação dos constructos para os dados de ambos os questionários contextuais (professores e alunos).

\section{Resultados e Discussão}

\section{Questionário do professor}

Do universo de docentes estudado, 97\% eram mulheres; 85\% lecionavam Língua Portuguesa e Matemática, $8 \%$ apenas Língua Portuguesa e 7\% apenas Matemática; constatouse, ainda, que $82 \%$ dos professores participaram de alguma atividade de formação continuada nos últimos dois anos. Das assertivas retiradas do questionário do professor, foram construídos sete fatores, dos quais quatro foram utilizados em análises subsequentes por apresentarem comportamento estatístico significante na explicação da expectativa do professor quanto aos resultados dos seus alunos. São eles: "Coesão e Trabalho em Equipe", "Indisciplina dos Alunos", "Falta de Colaboração dos Pais" e "Carência de Materiais e Instalações". Não obtiveram comportamento estatisticamente significante, neste trabalho, os seguintes fatores: "Percepções acerca do Ano Passado", "Perspectivas para Este Ano" e "Influência do Diretor no trabalho do Professor". Os fatores "Coesão e Trabalho em Equipe" e "Influência do Diretor no trabalho do Professor" foram construídos por meio de soluções unidimensionais, e os demais, por meio de soluções multidimensionais. A seguir, serão descritos cada um desses fatores.

O fator "Coesão e Trabalho em Equipe" reflete o planejamento conjunto do conteúdo programático entre professores, a participação na discussão e na troca de ideias acerca do projeto pedagógico da escola, e em que medida a troca de ideias influencia o ensino que a escola oferece aos seus alunos. Na Tabela 1, são representados o fator e suas assertivas mais associadas:

Os demais fatores foram extraídos por meio de um modelo multidimensional, obtido após procedimento de rotação
Varimax. A matriz de componentes rotacionados do modelo de análise fatorial é mostrada na Tabela 2.

Os dois primeiros fatores podem ser denominados de "Percepções acerca do Ano Passado" e "Perspectivas para Este Ano" por terem cargas elevadas em frases que incluem a percepção de como a situação se encontrava no ano anterior e de quais seriam as perspectivas para o ano corrente (2006). Tais fatores não foram utilizados em análise subsequente por não serem estatisticamente significantes. Os demais fatores, levados em consideração nas análises, estão enumerados a seguir.

A "Falta de Colaboração dos Pais" ( $3^{\circ}$ fator) refere-se à falta de apoio dos pais na aprendizagem do filho, mas também à falta de disciplina dos alunos e à frequência destes às aulas. Assim, na percepção dos professores, a falta de apoio dos pais na aprendizagem dos alunos está associada à indisciplina e à frequência irregular às aulas.

A "Indisciplina dos Alunos segundo os Professores" (4 fator) está relacionada, é claro, à assertiva sobre a falta de disciplina dos alunos, e também ao fato de que os alunos da escola desrespeitam o professor, à intimidação de colegas e, ainda, se há propensão ao uso de álcool e de drogas. Vale destacar que os professores, cuja percepção é mais aguçada em relação à indisciplina dos alunos, tendem a identificar a insensibilidade dos outros professores diante das necessidades individuais dos alunos.

"Carência de Materiais e Instalações na Escola" (5 fator) relaciona-se à assertiva sobre as más condições das instalações da escola e àquela relacionada à carência de materiais didáticos.

\section{Questionário dos alunos}

A população estudada conta com $50,4 \%$ de meninos. $\mathrm{O}$ percentual de alunos pardos revelou-se o mais alto (42\%), seguido de brancos $(33,5 \%)$, de pretos $(15 \%)$ e de outros $(9,5 \%)$.

A defasagem do aluno foi calculada pela diferença entre a sua idade e a idade recomendada para se cursar a série referida (neste caso, 10 anos de idade para a $4^{\mathrm{a}}$ série), admitindo-se uma tolerância para aqueles que completassem 11 anos no segundo semestre. Vale ressaltar que o percentual de alunos que se encontrava abaixo da idade recomendada (com 10 anos incompletos) foi bastante expressivo, em torno de $31 \%$, e o percentual de defasados foi de aproximadamente $24 \%$.

Cerca de $48 \%$ dos alunos responderam que recebiam "Bolsa-Família", e, em uma análise específica, mostrou-se que essa variável constituiu um melhor indicador da condição socioeconômica do que os indicadores construídos a partir dos itens de conforto (posse de bens materiais). Uma possível explicação para esse fato é que esta se trata de uma variável categórica binária, menos sujeita a erros de coleta de dados. Portanto, essa variável foi preferida nos modelos de regressão construídos para explicar a expectativa do professor quanto ao resultado do aluno.

As respostas atribuídas às frases, na terceira parte do questionário, foram recodificadas por um critério baseado no número aproximado de dias letivos, seguindo a regra: à opção A - "Em todas as aulas", atribuiu-se o valor 200 
Tabela 1. Matriz de componentes principais do fator coesão e trabalho em equipe - Questionário do professor.

\begin{tabular}{|c|c|c|}
\hline Assertivas & Componente & Comunalidade \\
\hline $\begin{array}{l}\text { Q.16 - O ensino que a escola oferece aos alunos é muito influenciado pela troca de ideias } \\
\text { entre os membros da equipe da escola }\end{array}$ & 0,74 & 0,55 \\
\hline $\begin{array}{l}\text { Q.37 - Nesta escola, tenho poucas oportunidades para discutir o conteúdo programático da } \\
\text { minha turma com a equipe da escola }\end{array}$ & $-0,70$ & 0,48 \\
\hline $\begin{array}{l}\text { Q.21 - O projeto educacional desta escola é consequência da troca de ideias entre os profes- } \\
\text { sores }\end{array}$ & 0,68 & 0,46 \\
\hline $\begin{array}{l}\text { Q.17 - Os professores desta escola se esforçam para coordenar o conteúdo das matérias entre } \\
\text { as diferentes séries? }\end{array}$ & 0,66 & 0,44 \\
\hline $\begin{array}{l}\text { Q.34 - Nesta escola, tenho poucas oportunidades em discutir ideias sobre ensino-aprendiza- } \\
\text { gem }\end{array}$ & $-0,66$ & 0,44 \\
\hline Q.31 - A equipe de professores leva em consideração minhas ideias & 0,64 & 0,41 \\
\hline Q.36 - O conteúdo programático entre diferentes séries não é planejado em equipe & $-0,62$ & 0,38 \\
\hline $\begin{array}{l}\text { Q.33 - Nesta escola, tenho dificuldade em compartilhar minhas preocupações e frustrações } \\
\text { profissionais com outros professores }\end{array}$ & $-0,57$ & 0,33 \\
\hline Q.32 - Eu levo em consideração as ideias de outros colegas & 0,56 & 0,32 \\
\hline Q.38 - Existem muitos projetos nesta escola e eu não consigo ter uma visão geral deles & $-0,51$ & 0,26 \\
\hline Q.13 - Participo das decisões relacionadas ao meu trabalho & 0,50 & 0,25 \\
\hline
\end{tabular}

Nota - Método de extração: componentes principais.

(aproximadamente 200 dias letivos); à $\mathrm{B}$ - "Na maioria das aulas", o valor 140; à C - "Em algumas aulas", o valor 60; e à opção D - "Nunca", valor 0. Excluindo-se a frase "O(A) professor(a) ajuda mais a uns do que a outros", foi realizada uma Análise Fatorial, obtendo-se uma solução de cinco fatores, com explicação de $54 \%$ da variância. De forma a facilitar a interpretação dos fatores, utilizou-se, também, a rotação seguindo o método Varimax. A matriz de componentes rotacionados é mostrada a seguir (ver Tabela 3) e, logo após, se faz uma interpretação dos fatores obtidos.

O primeiro fator, denominado de "Interesse e Dedicação do Professor", está associado às seguintes assertivas: "O(A) professor(a) está disponível para esclarecer as dúvidas dos alunos", "O(A) professor(a) mostra interesse no aprendizado de todos os alunos" e "O(A) professor(a) se esforça para ajudar".

O segundo fator, "Barulho e Bagunça na Sala de Aula", apresenta correlação com as frases que se referem à espera do professor pelo silêncio, à ocorrência de barulho e desordem na sala de aula, bem como à saída dos alunos antes do término das aulas.
O fator "Exigência do Professor" associa-se, na percepção do aluno, ao fato do professor exigir trabalhos bem feitos, estudo e atenção de seus alunos.

O fator "Falta de Compromisso dos Professores e Alunos para com a Aula" engloba o compromisso do professor com sua frequência às aulas e o hábito dos alunos saírem antes do término das aulas.

O último fator, "Compromisso do Professor com o Dever", associa-se, na percepção do aluno, ao empenho do professor em mostrar, em discutir e em corrigir o dever de casa.

Calcularam-se os valores dos escores de cada fator para cada aluno e, posteriormente, a sua média nas respectivas turmas. A média dos escores se constitui em um indicador mais fidedigno do perfil do professor e da atmosfera em sala de aula do que cada percepção individual dos alunos. Também foi incluído, nas análises, o percentual de alunos pretos ("Percentual de Pretos"), de meninos ("Percentual de Alunos do Gênero Masculino") e de alunos que recebem Bolsa-Família ("Percentual de Alunos que Recebem BolsaFamília"), bem como a defasagem média ("Defasagem Média 
Tabela 2. Matriz de componentes rotacionados - Questionário do professor.

\begin{tabular}{|c|c|c|c|c|c|c|}
\hline \multirow{2}{*}{ Assertivas } & \multicolumn{5}{|c|}{ Componentes } & \multirow{2}{*}{ Comunalidade } \\
\hline & 1 & 2 & 3 & 4 & 5 & \\
\hline $\begin{array}{l}\text { Q.40 - No ano passado o(a) diretor(a) promovia mais } \\
\text { atividades inovadoras }\end{array}$ & $\mathbf{0 , 8 8}$ & 0,08 & 0,07 & 0,03 & 0,03 & 0,79 \\
\hline $\begin{array}{l}\text { Q.39 - No ano passado, as reuniões promovidas pela } \\
\text { direção eram mais objetivas }\end{array}$ & 0,84 & 0,08 & 0,09 & 0,03 & 0,03 & 0,72 \\
\hline $\begin{array}{l}\text { Q.41 - No ano passado, o clima entre a direção e os } \\
\text { professores era melhor }\end{array}$ & $\mathbf{0 , 8 3}$ & $-0,02$ & 0,06 & 0,07 & 0,01 & 0,71 \\
\hline $\begin{array}{l}\text { Q.42 - No ano passado, as metas da escola estavam } \\
\text { mais focalizadas no aprendizado dos alunos do que } \\
\text { neste ano }\end{array}$ & 0,75 & $-0,04$ & 0,01 & 0,11 & 0,13 & 0,60 \\
\hline $\begin{array}{l}\text { Q.44 - Neste ano, o(a) diretor(a) está mais } \\
\text { motivado(a) }\end{array}$ & $-0,00$ & $\mathbf{0 , 8 8}$ & 0,02 & $-0,01$ & $-0,02$ & 0,77 \\
\hline $\begin{array}{l}\text { Q.43 - Neste ano, as reuniões promovidas pela } \\
\text { direção da escola estão focalizando melhor os reais } \\
\text { problemas da escola }\end{array}$ & 0,03 & 0,86 & 0,04 & 0,00 & $-0,00$ & 0,74 \\
\hline $\begin{array}{l}\text { Q.45 - Neste ano, o planejamento da escola envol- } \\
\text { veu a definição de metas mais claras do que no ano } \\
\text { passado }\end{array}$ & 0,05 & 0,85 & 0,02 & 0,02 & 0,01 & 0,72 \\
\hline $\begin{array}{l}\text { Q.47 - A aprendizagem é prejudicada pela falta de } \\
\text { apoio dos pais ao aprendizado do aluno }\end{array}$ & 0,04 & 0,01 & 0,79 & 0,00 & 0,06 & 0,63 \\
\hline $\begin{array}{l}\text { Q.46 - Nesta escola, nos ciclos e séries em que você } \\
\text { leciona, a aprendizagem é prejudicada pela frequên- } \\
\text { cia irregular dos alunos }\end{array}$ & 0,09 & 0,08 & 0,64 & $-0,02$ & 0,22 & 0,48 \\
\hline $\begin{array}{l}\text { Q.48 - A aprendizagem é prejudicada pela falta de } \\
\text { disciplina dos alunos }\end{array}$ & 0,07 & $-0,01$ & 0,70 & $\mathbf{0 , 4 0}$ & 0,04 & 0,66 \\
\hline $\begin{array}{l}\text { Q.52 - A aprendizagem é prejudicada pela falta de } \\
\text { respeito dos alunos para com os professores }\end{array}$ & 0,09 & $-0,02$ & 0,54 & 0,62 & 0,04 & 0,69 \\
\hline $\begin{array}{l}\text { Q.54 - A aprendizagem é prejudicada por alunos que } \\
\text { intimidam e perturbam os colegas }\end{array}$ & 0,04 & $-0,00$ & 0,47 & $\mathbf{0 , 7 0}$ & $-0,02$ & 0,71 \\
\hline $\begin{array}{l}\text { Q.53 - A aprendizagem é prejudicada pelo uso de } \\
\text { álcool e drogas por parte dos alunos }\end{array}$ & 0,03 & 0,05 & $-0,02$ & 0,75 & 0,14 & 0,59 \\
\hline $\begin{array}{l}\text { Q.51 - A aprendizagem é prejudicada pela indiferen- } \\
\text { ça dos professores diante das necessidades individu- } \\
\text { ais dos alunos }\end{array}$ & 0,18 & $-0,04$ & $-0,05$ & 0,57 & 0,38 & 0,50 \\
\hline $\begin{array}{l}\text { Q.49 - A aprendizagem é prejudicada pelas más } \\
\text { condições das instalações da escola }\end{array}$ & 0,11 & 0,00 & 0,12 & 0,13 & 0,82 & 0,71 \\
\hline $\begin{array}{l}\text { Q.50 - A aprendizagem é prejudicada pela falta de } \\
\text { material didático-pedagógico }\end{array}$ & 0,09 & $-0,01$ & 0,18 & 0,15 & $\mathbf{0 , 8 0}$ & 0,71 \\
\hline Percentual da variância explicada & 17,6 & 14,1 & 12,3 & 13,2 & 9,8 & \\
\hline
\end{tabular}

Nota - Método de extração: componentes principais; rotação: método Varimax com normalização de Kaiser; os valores em negrito se referem às cargas utilizadas para se interpretar os fatores. 
Tabela 3. Matriz de componentes rotacionados - Questionário do aluno.

\begin{tabular}{|c|c|c|c|c|c|c|}
\hline \multirow[t]{2}{*}{ Assertivas } & \multicolumn{5}{|c|}{ Componentes } & \multirow[t]{2}{*}{ Comunalidades } \\
\hline & 1 & 2 & 3 & 4 & 5 & \\
\hline Q.27 - Professor esclarece as dúvidas & $\mathbf{0 , 7 0}$ & 0,02 & 0,06 & $-0,07$ & 0,07 & 0,50 \\
\hline $\begin{array}{l}\text { Q.28 - Professor explica enquanto neces- } \\
\text { sário }\end{array}$ & 0,65 & $-0,02$ & 0,07 & 0,03 & 0,09 & 0,43 \\
\hline Q.29 - Professor se esforça para ajudar & 0,65 & $-0,03$ & 0,12 & $-0,04$ & 0,09 & 0,44 \\
\hline Q.26 - Alunos expressam opiniões & 0,63 & 0,01 & 0,02 & 0,06 & 0,09 & 0,41 \\
\hline $\begin{array}{l}\text { Q.25 - Professor interessado no aprendi- } \\
\text { zado }\end{array}$ & 0,61 & $-0,04$ & 0,22 & $-0,05$ & 0,03 & 0,43 \\
\hline Q.22 - Professor tem que esperar silêncio & 0,01 & 0,75 & $-0,07$ & 0,06 & $-0,00$ & 0,57 \\
\hline Q.31 - Barulho e desordem na sala & 0,00 & 0,69 & 0,02 & 0,21 & $-0,00$ & 0,52 \\
\hline Q.30 - Alunos atentos ao professor & 0,23 & $-0,40$ & 0,07 & 0,65 & 0,08 & 0,65 \\
\hline $\begin{array}{l}\text { Q.33 - Alunos saem antes do término da } \\
\text { aula }\end{array}$ & $-0,09$ & 0,32 & $-0,03$ & 0,66 & $-0,02$ & 0,55 \\
\hline Q.35 - Professor falta & $-0,11$ & 0,27 & $-0,01$ & 0,66 & $-0,04$ & 0,52 \\
\hline Q.23 - Professor exige estudo e atenção & 0,14 & 0,01 & $\mathbf{0 , 8 1}$ & $-0,02$ & 0,07 & 0,68 \\
\hline $\begin{array}{l}\text { Q.24 - Professor exige trabalhos bem } \\
\text { feitos }\end{array}$ & 0,20 & $-0,01$ & 0,78 & 0,02 & 0,05 & 0,65 \\
\hline Q.21 - Professor corrige dever & 0,07 & $-0,15$ & $-0,02$ & $-0,05$ & $\mathbf{0 , 8 4}$ & 0,74 \\
\hline $\begin{array}{l}\text { Q.32 - Professor mostra e discute os } \\
\text { deveres }\end{array}$ & 0,23 & 0,14 & 0,16 & 0,05 & 0,62 & 0,49 \\
\hline Percentual da variância explicada & 16,40 & 10,10 & 9,70 & 9,70 & 8,20 & \\
\hline
\end{tabular}

Nota - Método de extração: componentes principais; rotação: método Varimax com normalização de Kaiser; os valores em negrito se referem às cargas utilizadas para se interpretar os fatores.

dos Alunos"), e a proficiência média em Língua Portuguesa e em Matemática na turma. As variáveis mais influentes são representadas na Tabela 4.

\section{Expectativa do Professor com Relação ao Desempenho do Aluno}

Com o objetivo de aprofundar o conhecimento da "expectativa" e da "sintonia" do professor quanto ao desempenho de seus alunos e de estabelecer possíveis relações dessas variáveis com as demais descritas anteriormente, foi realizado um 'experimento' no teste do PROEB-2006. Esse 'experimento' consistiu na inserção de 12 imagens de itens, pertencentes aos testes cognitivos aplicados aos alunos, no questionário aplicado aos professores, das quais seis eram questões de Matemática e seis de Língua Portuguesa. Solicitou-se, então, ao professor a sua estimativa acerca da parcela da turma que acertaria o item (ver Figura 1).

Tendo em vista uma aproximação das alternativas a uma escala intervalar, atribuíram-se às respostas dos professores os seguintes valores: todos $(100 \%)$, mais da metade $(75 \%)$, metade $(50 \%)$, menos da metade $(25 \%)$ e uns poucos $(10 \%)$. Obteve-se, assim, a distribuição das expectativas dos professores acerca do acerto de cada item pela turma e o seu percentual geral de acerto. Conforme se observa na Tabela 5, uma parte razoável dos professores tem uma ideia do resultado alcançado pela turma. Há, também, um subconjunto expressivo de professores que superestimam os resultados 
Tabela 4. Variáveis utilizadas nos modelos de regressão.

\begin{tabular}{|c|c|c|c|}
\hline Nível da variável & Descrição das variáveis & Variável & Fonte \\
\hline \multirow[t]{2}{*}{ Aluno } & $\begin{array}{l}\text { Variáveis referentes à condição socioe- } \\
\text { conômica do aluno }\end{array}$ & $\begin{array}{l}\text { Gênero Masculino } \\
\text { Cor Preta } \\
\text { Bolsa-Família }\end{array}$ & \multirow[t]{2}{*}{$\begin{array}{l}\text { Questionário do } \\
\text { Aluno }\end{array}$} \\
\hline & $\begin{array}{l}\text { Variáveis referentes às dificuldades } \\
\text { escolares }\end{array}$ & Defasagem do Aluno & \\
\hline \multirow{4}{*}{ Professor e turma } & $\begin{array}{l}\text { Variáveis referentes às questões acerca } \\
\text { da escola, na percepção dos professores }\end{array}$ & $\begin{array}{l}\text { Coesão e Trabalho em Equipe } \\
\text { Falta de Colaboração dos Pais } \\
\text { Indisciplina dos Alunos } \\
\text { Carência de Materiais e Instalações }\end{array}$ & $\begin{array}{l}\text { Questionário do } \\
\text { Professor }\end{array}$ \\
\hline & $\begin{array}{l}\text { Variáveis referentes ao empenho do } \\
\text { professor, segundo seus alunos }\end{array}$ & $\begin{array}{c}\text { Interesse e Dedicação do Professor } \\
\text { Exigência do Professor } \\
\text { Compromisso do Professor } \\
\text { com o Dever }\end{array}$ & \multirow[t]{3}{*}{$\begin{array}{l}\text { Questionário do } \\
\text { Aluno }\end{array}$} \\
\hline & $\begin{array}{l}\text { Variáveis referentes ao clima em sala } \\
\text { de aula }\end{array}$ & $\begin{array}{c}\text { Falta de Compromisso dos Professores } \\
\text { e Alunos para com a Aula } \\
\text { Barulho e Bagunça na Sala de Aula }\end{array}$ & \\
\hline & $\begin{array}{l}\text { Variáveis referentes à condição socioe- } \\
\text { conômica da turma }\end{array}$ & $\begin{array}{c}\text { Percentual de Alunos do Gênero Mas- } \\
\text { culino } \\
\text { Percentual de Pretos } \\
\text { Percentual de Alunos que Recebem } \\
\text { Bolsa-Família } \\
\text { Defasagem Média dos Alunos }\end{array}$ & \\
\hline
\end{tabular}

Tabela 5. Distribuição das expectativas do professor em relação ao percentual de alunos que responderão corretamente a cada item apresentado.

\begin{tabular}{lcccccccc}
\hline & & \multicolumn{7}{c}{ Percentual esperado (Expectativa declarada por item) } \\
\cline { 2 - 8 } Questões & $\begin{array}{c}\text { Percentual de } \\
\text { acerto }\end{array}$ & Todos & $\begin{array}{c}\text { Mais da } \\
\text { metade }\end{array}$ & Metade & $\begin{array}{c}\text { Menos da } \\
\text { metade }\end{array}$ & Uns poucos & $\begin{array}{c}\text { Nenhum } \\
\text { Não respon- } \\
\text { deram }\end{array}$ \\
\hline Português 1 & 57,16 & 19,40 & 52,57 & 9,03 & 2,53 & 0,92 & 0,03 & 15,52 \\
Português 2 & 43,28 & 11,95 & 49,67 & 16,08 & 5,40 & 1,08 & 0,04 & 15,78 \\
Português 3 & 76,72 & 26,33 & 44,28 & 9,48 & 3,22 & 0,83 & 0,10 & 15,76 \\
Português 4 & 82,55 & 16,23 & 46,59 & 15,06 & 5,47 & 0,91 & 0,04 & 15,71 \\
Português 5 & 62,10 & 8,63 & 39,32 & 23,60 & 11,03 & 1,52 & 0,16 & 15,73 \\
Português 6 & 33,89 & 6,11 & 34,12 & 26,92 & 14,54 & 1,94 & 0,10 & 16,28 \\
Matemática 1 & 64,29 & 28,26 & 42,79 & 9,07 & 2,69 & 0,37 & 0,01 & 16,81 \\
Matemática 2 & 75,50 & 19,05 & 46,66 & 13,03 & 4,04 & 0,76 & 0,13 & 16,33 \\
Matemática 3 & 81,62 & 26,78 & 40,54 & 11,52 & 4,02 & 0,57 & 0,08 & 16,49 \\
Matemática 4 & 74,12 & 41,53 & 36,42 & 4,34 & 0,94 & 0,22 & 0,04 & 16,52 \\
Matemática 5 & 83,54 & 18,29 & 43,62 & 15,60 & 5,34 & 0,53 & 0,07 & 16,54 \\
Matemática 6 & 57,15 & 35,10 & 38,0 & 8,07 & 1,93 & 0,32 & 0,04 & 16,52 \\
\hline
\end{tabular}


dos alunos e outro menos expressivo que os subestimam. Por exemplo, o item 4 de Matemática teve o seu resultado superestimado por boa parte dos professores, e o item 2 de Língua Portuguesa teve seu resultado subestimado; esta foi uma das razões que tornou difícil se medir a sintonia do resultado com a expectativa, considerando cada um dos itens, em separado. Já que o objetivo deste trabalho foi confrontar as expectativas de acerto dos professores com os resultados de seus alunos, torna-se necessário, então, obter uma medida única da "Sintonia" entre a expectativa do professor quanto aos resultados dos alunos e os resultados observados no teste.

\section{Medida da sintonia entre o desempenho do aluno no teste e a expectativa do professor}

Para compor uma medida geral da Sintonia para cada professor, tomou-se para cada item a diferença entre o percentual de acerto esperado e o percentual de acerto observado na sua turma. A média dessas diferenças, utilizando-se todas as questões, compôs uma medida geral denominada de "Diferença Entre o Esperado e o Observado". À medida que o valor absoluto dessa diferença se distancia de zero, menos o professor acerta o desempenho da turma nas questões selecionadas do teste. A "Diferença Entre o Esperado e o Observado" pode ser considerada, então, uma forma de se aferir a sintonia da expectativa do professor com o desempenho de sua turma.

Para efeito de análise, consideraram-se professores "sintonizados" aqueles que apresentaram valores para a "Diferença Entre o Esperado e o Observado" entre -10\% e $+10 \%$, ou seja, apresentaram expectativas muito próximas do desempenho efetivamente obtido. Esses professores, caracterizados dessa forma, correspondem a $47 \%$ do total. Aqueles professores que erraram os resultados dividiram-se entre os que erraram por superestimar, apresentando diferença entre o esperado e o observado maior que $10 \%$, e os que erraram por subestimar, apresentando diferença menor que $-10 \%$. A categoria denominada "sintonizados" foi colocada como focal, recebendo valor igual a 1 e os "não sintonizados", como referência, com valor igual a 0 .

\section{Expectativa geral de acerto}

A expectativa do professor quanto ao desempenho do aluno foi medida para cada item, individualmente. No entanto, para maior conveniência das análises, torna-se necessário saber se é possível representar em uma única medida todas as expectativas obtidas em todos os itens. Não sendo possível, existiriam múltiplas expectativas associadas a determinados subgrupos de itens. Para responder a essa questão, utilizou-se a técnica da Análise Fatorial, que apontou a existência de um único fator dominante, que explicou $53 \%$ da variabilidade (o segundo fator explicou apenas 9\%). Esse fator se relaciona com todas as questões com uma carga elevada e valores muito próximos entre si, algo em torno de 0,73. Tem-se, assim, uma estrutura facilmente interpretável como unidimensional, mostrada na Tabela 6. Conclui-se, então, que as expectativas

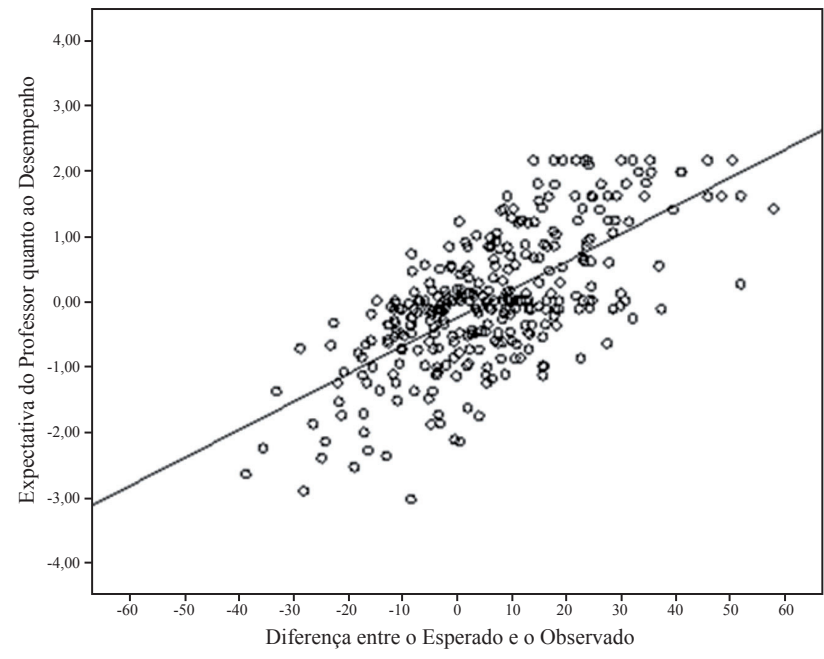

Figura 2. Expectativa do professor quanto ao desempenho do aluno em função da diferença entre o desempenho esperado e o observado.

individuais podem ser representadas por uma única medida denominada "Expectativa" do professor quanto ao desempenho do aluno, que foi ainda padronizada, isto é, extraída com média igual a 0 e desvio padrão igual a 1 .

\section{A relação entre a sintonia e a expectativa}

A relação entre as duas medidas é bastante relevante, como se pode ver por meio do coeficiente de correlação de Pearson, que apresentou um valor razoavelmente forte e positivo $(\mathrm{r}=0,62)$, mostrando que quanto maior é a "Expectativa" do professor quanto ao desempenho do aluno, maior

Tabela 6. Matriz de cargas da Análise Fatorial da "Expectativa" do professor quanto à parcela de respostas corretas em 12 itens do PROEB-2006.

\begin{tabular}{lccc}
\hline Teste & Item & Componente & Comunalidade \\
\hline & 1 & 0,75 & 0,57 \\
Língua & 2 & 0,74 & 0,54 \\
Portuguesa & 3 & 0,70 & 0,49 \\
& 4 & 0,75 & 0,57 \\
& 5 & 0,73 & 0,53 \\
& 6 & 0,70 & 0,49 \\
\hline \multirow{2}{*}{ Matemática } & 1 & 0,70 & 0,48 \\
& 2 & 0,75 & 0,57 \\
& 3 & 0,72 & 0,52 \\
& 5 & 0,72 & 0,52 \\
& 6 & 0,74 & 0,55 \\
& & 0,75 & 0,56 \\
\hline
\end{tabular}


será a "Diferença Entre o Esperado e o Observado". Ou seja, professores com alta expectativa tendem a superestimar os acertos dos alunos, e vice-versa. Na Figura 2 pode-se observar claramente essa relação.

Como um dos objetivos do presente estudo é identificar as variáveis contextuais dos alunos, professores, diretores e escola associadas à "Sintonia" e à "Expectativa" do professor acerca do desempenho dos alunos, construiu-se modelos de regressão específicos para identificar essas relações.

\section{Um modelo explicativo para a "Expectativa" do professor quanto ao resultado do aluno}

Para uma análise preliminar de como a "Expectativa" se associa às demais variáveis, a variável original contínua foi recodificada em uma variável ordinal com os seguintes níveis: baixo, quando a "Expectativa" apresenta valor menor ou igual a - 0,5 ; mediano, quando o valor situa-se entre $-0,5$ e 0,5 ; e alto, se o valor é maior ou igual a 0,5 . Para cada nível da nova representação da "Expectativa" do professor, foram calculadas as médias e os percentuais das demais variáveis. A Tabela 7 apresenta esses resultados. Essa tabela mostra, por exemplo, que maiores níveis de "Expectativa" associam-se à maiores níveis de condição socioeconômica da turma e maior nível de "Interesse e Dedicação do Professor".

Porém, a análise pelas médias e percentuais da Tabela 7 não é suficiente para compreender todas as associações existentes, muito menos separar o efeito "líquido" de cada variável, quando controlado o efeito das demais. A forma como se constrói a variável recodificada pode tornar mais ou menos evidentes as relações existentes entre a expectativa e as demais variáveis. Por esses motivos, foi realizada a seguinte sequência de análises:

(i) Inicialmente, foram construídos modelos de Regressão Linear Simples com cada variável independente, a fim de se mensurar sua influência sem nenhuma forma de controle;

(ii) Num segundo momento, foram inseridas as variáveis contextuais do professor e da turma para que fosse possível analisar suas relações com a expectativa do professor, tendo sido controlado o efeito das demais, conforme apresentado no Modelo 1 da Tabela 8;

(iii) Por fim, as variáveis Sintonia do Professor e proficiências médias da turma em Língua Portuguesa e em Matemática foram adicionadas no Modelo 2. O objetivo era constatar a maneira pela qual o professor forma uma expectativa acerca do desempenho de sua turma, em função das variáveis contextuais para alunos de mesma habilidade cognitiva.

Os resultados dos modelos indicados acima são apresentados na Tabela 8 .

Os coeficientes dos Modelos de Regressão Linear Simples foram sempre significantes. De fato, as variáveis escolhidas para a construção do modelo foram apontadas, em estudos anteriores, como importantes para a explicação das proficiências individuais do aluno (Soares, 2003). É natural admitir que pelo menos parte delas tenha também importância na explicação da "Expectativa" do professor, isso porque a expectativa está fortemente correlacionada com a proficiência média da turma. No entanto, a principal informação é o valor apresentado pelos coeficientes nesses modelos de regressão simples e o grau de significância, pois são utilizados como base em comparações subse-

Tabela 7. Médias e percentuais das variáveis contextuais por cada nível de "Expectativa do Professor".

\begin{tabular}{|c|c|c|c|c|}
\hline \multirow{2}{*}{ Variáveis Contextuais } & \multicolumn{3}{|c|}{ Níveis de Expectativa } & \multirow[b]{2}{*}{ Total } \\
\hline & Baixo & Mediano & Alto & \\
\hline Interesse e Dedicação do Professor & $-0,14$ & 0,00 & 0,13 & 0,00 \\
\hline Exigência do Professor & $-0,07$ & 0,00 & 0,06 & 0,00 \\
\hline Compromisso do Professor com o Dever & $-0,07$ & 0,01 & 0,04 & 0,00 \\
\hline Barulho e Bagunça na Sala de Aula & 0,15 & 0,00 & $-0,13$ & 0,00 \\
\hline $\begin{array}{l}\text { Falta de Compromisso dos Professores e } \\
\text { Alunos para com a Aula }\end{array}$ & 0,18 & 0,00 & $-0,16$ & 0,00 \\
\hline Percentual de Alunos do Gênero Masculino & 53,0 & 51,0 & 50,0 & 51,0 \\
\hline Percentual de Pretos & 17,0 & 15,0 & 14,0 & 15,0 \\
\hline Defasagem Média dos Alunos (anos) & 1,73 & 1,57 & 1,50 & 1,59 \\
\hline Percentual de Alunos que Recebem Bolsa-Família & 57,0 & 50,0 & 45,0 & 50,0 \\
\hline Indisciplina dos Alunos & 0,06 & 0,00 & $-0,05$ & 0,00 \\
\hline Falta de Colaboração dos Pais & 0,21 & $-0,01$ & $-0,18$ & 0,00 \\
\hline Carência de Materiais e Instalações & 0,10 & $-0,01$ & $-0,08$ & 0,00 \\
\hline Coesão e Trabalho em Equipe & $-0,17$ & 0,04 & 0,13 & 0,01 \\
\hline Percentual de Professores em Sintonia & 53 & 57 & 26 & 47 \\
\hline Proficiência em Língua Portuguesa & 174,5 & 187,4 & 196,9 & 186,8 \\
\hline Proficiência em Matemática & 179,5 & 193,2 & 203,6 & 192,6 \\
\hline Percentual sobre a população geral & 26,1 & 44,5 & 28,4 & 100 \\
\hline
\end{tabular}

Nota - Todos os fatores possuem média 0 e desvio padrão 1. 
Tabela 8. Modelos de regressão linear para a "Expectativa do Professor".

\begin{tabular}{|c|c|c|c|c|c|c|}
\hline & \multicolumn{2}{|c|}{ Regressão Linear Simples } & \multicolumn{2}{|c|}{ Modelo 1} & \multicolumn{2}{|c|}{ Modelo 2} \\
\hline & Coeficientes & $\mathrm{p}$ & Coeficientes & $\mathrm{p}$ & Coeficientes & $\mathrm{p}$ \\
\hline Intercepto & -- & $-{ }_{-}-$ & 0,808 & 0,000 & $-1,884$ & 0,000 \\
\hline $\begin{array}{l}\text { Interesse e Dedicação do } \\
\text { Professor }\end{array}$ & 0,110 & 0,000 & 0,023 & 0,020 & $-0,016$ & 0,079 \\
\hline Exigência do Professor & $\mathbf{0 , 0 5 7}$ & $\mathbf{0 , 0 0 0}$ & 0,015 & 0,117 & 0,001 & 0,871 \\
\hline $\begin{array}{l}\text { Compromisso do Professor } \\
\text { com o Dever }\end{array}$ & 0,046 & $\mathbf{0 , 0 0 0}$ & 0,015 & 0,099 & 0,007 & 0,451 \\
\hline $\begin{array}{l}\text { Barulho e Bagunça na Sala } \\
\text { de Aula }\end{array}$ & $-0,126$ & $\mathbf{0 , 0 0 0}$ & $-0,062$ & $\mathbf{0 , 0 0 0}$ & $-0,016$ & 0,079 \\
\hline $\begin{array}{l}\text { Falta de Compromisso do } \\
\text { Professor e do Aluno para } \\
\text { com a Aula }\end{array}$ & $-0,158$ & 0,000 & $-0,076$ & 0,000 & $-0,013$ & 0,184 \\
\hline $\begin{array}{l}\text { Percentual de Alunos do } \\
\text { Gênero Masculino }\end{array}$ & $-0,793$ & 0,000 & $-0,401$ & 0,000 & $-0,193$ & 0,008 \\
\hline Percentual de Pretos & $-1,410$ & $\mathbf{0 , 0 0 0}$ & $-0,562$ & $\mathbf{0 , 0 0 0}$ & $-0,256$ & 0,002 \\
\hline $\begin{array}{l}\text { Percentual de Alunos que } \\
\text { Recebem Bolsa-Família }\end{array}$ & $-1,185$ & 0,000 & $-0,807$ & 0,000 & $-0,257$ & 0,000 \\
\hline $\begin{array}{l}\text { Defasagem Média dos } \\
\text { Alunos (anos) }\end{array}$ & $-0,309$ & $\mathbf{0 , 0 0 0}$ & $-0,067$ & 0,000 & 0,001 & 0,958 \\
\hline Indisciplina dos Alunos & $-0,048$ & 0,000 & $-0,022$ & 0,017 & $-0,016$ & 0,063 \\
\hline $\begin{array}{l}\text { Falta de Colaboração dos } \\
\text { Pais }\end{array}$ & $-0,157$ & $\mathbf{0 , 0 0 0}$ & $-0,106$ & 0,000 & $-0,083$ & 0,000 \\
\hline $\begin{array}{l}\text { Carência de Materiais e } \\
\text { Instalações }\end{array}$ & $-0,074$ & 0,000 & $-0,038$ & 0,000 & $-0,028$ & 0,002 \\
\hline $\begin{array}{l}\text { Coesão e Trabalho em } \\
\text { Equipe }\end{array}$ & 0,140 & $\mathbf{0 , 0 0 0}$ & 0,100 & 0,000 & 0,097 & 0,000 \\
\hline Sintonia & $-0,379$ & 0,000 & $-\ldots$ & $-{ }_{-}-{ }_{-}$ & $-0,515$ & 0,000 \\
\hline $\begin{array}{l}\text { Proficiência em Língua } \\
\text { Portuguesa }\end{array}$ & 0,014 & 0,000 & --- & --- & 0,008 & 0,000 \\
\hline Proficiência em Matemática & $\mathbf{0 , 0 1 2}$ & $\mathbf{0 , 0 0 0}$ & & & 0,005 & 0,000 \\
\hline
\end{tabular}

quentes à medida que se introduzem as demais variáveis de controle.

Como se pode observar no Modelo 1, apesar de na avaliação dos alunos o grau de "Exigência do Professor" e de “Compromisso do Professor com o Dever" serem características que em análises anteriores mostraram-se extremamente relevantes para a explicação da proficiência dos alunos (Soares, 2005), essas características não apresentaram, aqui, impacto substancial na "Expectativa" do professor quanto ao desempenho do aluno. A variável "Interesse e Dedicação do Professor" manteve-se significante (ao nível de 2\%), porém foi observada uma queda considerável no valor de seu coeficiente. Isso é um indicativo de que a expectativa independe do perfil do professor nesse nível de controle. Por outro lado, foram relevantes as influências das variáveis representativas:

(i) das características de turma, como "Percentual de Alunos do Gênero Masculino", "Percentual de Pretos", de alunos de baixa condição socioeconômica, representada pela variável "Percentual de Alunos que Recebem Bolsa-Família" e pela "Defasagem Média dos Alunos";

(ii) da atmosfera em sala de aula, constituída pelo grau de "Barulho e Bagunça em Sala de Aula" e de "Descomprometimento dos Alunos e do Professor para com as Aulas"; (iii) das atitudes do professor frente a algumas condições escolares, como a "Carência de Materiais e Instalações", a "Falta de Colaboração dos Pais" e a "Coesão e Trabalho em Equipe".

Individualmente, a "Expectativa" está correlacionada ao desempenho da turma ( $\mathrm{r}=0,36$ para Língua Portuguesa e $\mathrm{r}=0,35$ para Matemática), podendo, de certa forma, ser construída pelo professor também a partir de um diagnóstico do desempenho, com base no conhecimento de seus alunos. Para entender como, além do diagnóstico do professor, outras variáveis contextuais afetam a expectativa do professor, no Modelo 2 foram introduzidas as variáveis indicadoras da proficiência da turma e da "Sintonia" do professor.

No Modelo 2 proposto, reforça-se a constatação de que as características do professor avaliadas pelos alunos, como o nível de "Exigência do Professor" e de "Compromisso do Professor com o Dever", não apresentam influências significativas sobre a "Expectativa" e o nível de "Interesse e Dedicação do Professor". Entretanto, continuaram significantes características da turma como "Percentual de Alunos do Gênero Masculino", "Percentual de Pretos" e "Percentual de Alunos que Recebem Bolsa-Família", e algumas atitudes do professor frente às condições escolares como a "Carência de Materiais e Instalações", a "Falta de Colaboração dos Pais" e a "Coesão e Trabalho em Equipe". Deixaram de ser 
significantes as variáveis representativas da atmosfera em sala de aula e a defasagem escolar.

Os resultados das análises apresentadas sugerem que, após serem controlados os níveis de "Sintonia" do professor acerca do desempenho da turma e as proficiências dos alunos, a explicação da "Expectativa" se baseia em atitudes do professor frente a algumas condições escolares e, principalmente, em características socioeconômicas de seus alunos.

Pode-se sugerir, então, que há, em geral, por parte dos professores, uma tendência a associar piores resultados a turmas com maior percentual de pretos, de alunos do sexo masculino e de alunos de baixa condição socioeconômica, independente dos reais níveis de habilidades cognitivas dos alunos.

\section{O impacto da sintonia e da expectativa nas proficiências individuais dos alunos}

A última análise realizada é a da influência que a "Sintonia" e a "Expectativa" do professor têm sobre as proficiências individuais dos alunos. Nessa análise, utilizam-se modelos de Regressão Hierárquicos que consideram a estrutura de agregação dos alunos em turmas e escolas. Nos modelos hierárquicos, as variáveis pertencem a diferentes níveis de agregação dos alunos, sendo que as características individuais dos alunos correspondem às variáveis de primeiro nível e as características da turma e do professor, às variáveis de segundo nível ${ }^{2}$. Os modelos são capazes de identificar a influência das variáveis de diversos níveis, assim como considerar possíveis interações existentes entre variáveis de níveis diferentes (para uma exposição mais aprofundada do uso de modelos hierárquicos, ver Lee, 2001).

Neste estudo, foram construídos dois Modelos de Regressão Hierárquicos que utilizaram como variáveis dependentes as proficiências em Língua Portuguesa e em Matemática. No primeiro nível, foram utilizadas como variáveis independentes as características estudadas e relacionadas à "Expectativa" e à "Sintonia". Assim, foram inseridas nos modelos as variáveis "Gênero Masculino", "Cor Preta", "Bolsa-Família" e "Defasagem do Aluno".

As características socioeconômicas das turmas foram utilizadas como variáveis explicativas do segundo nível. Para isso, calcularam-se as médias e os percentuais das características individuais dos alunos, obtendo-se as seguintes variáveis: "Percentual de Alunos que Recebem BolsaFamília", "Percentual de Pretos", "Percentual de Alunos do Gênero Masculino" e "Defasagem Média dos Alunos". Além dessas, foram inseridas todas as demais variáveis obtidas no questionário do professor, anteriormente utilizadas para compor os modelos da "Expectativa". Finalmente, incluíramse nos modelos as variáveis "Expectativa" e "Sintonia". Os coeficientes dos modelos construídos são apresentados na Tabela 9.

Inicialmente, observam-se os efeitos já esperados e relatados pela literatura e em estudos anteriores (Soares, 2005). Variáveis indicadoras das condições socioeconômicas e escolares da turma, como "Percentual de Alunos que Re-

2 Há uma correspondência entre alunos e turmas adequada neste estudo, uma vez que $85 \%$ dos professores lecionam ambas as disciplinas. cebem Bolsa-Família", "Percentual de Pretos", "Percentual de Alunos do Gênero Masculino" e "Defasagem Média dos Alunos", inseridas no segundo nível, apresentaram-se significantes mesmo quando essas características são consideradas no nível do aluno (primeiro nível). Pode-se, assim, interpretar esses resultados da seguinte maneira: a concentração de alunos pretos, de defasados, de meninos e de alunos de baixa condição socioeconômica na turma tende a diminuir a proficiência, não só dos alunos com essas características individualmente, mas também de todos os demais inseridos na mesma turma.

Também no segundo nível, foi significante a influência positiva das variáveis "Interesse e Dedicação do Professor" e "Exigência do Professor", e apresentou-se significante o efeito negativo do "Barulho e Bagunça na Sala de Aula" e do "Descaso do Professor e do Aluno para com a Aula". No entanto, variáveis que descrevem as percepções dos professores acerca de uma série de questões escolares, como a "Indisciplina dos Alunos", a "Carência de Materiais e Instalações" e a "Coesão e Trabalho em Equipe" não se apresentaram significantes; e a "Falta de Colaboração dos Pais" só se apresentou significante no modelo de Matemática.

De uma maneira geral, pode-se afirmar que, quando controladas as demais variáveis, as características do professor e da atmosfera em sala de aula apresentam-se significativamente mais importantes, segundo os alunos. Já as percepções dos professores acerca do ambiente escolar não se mostram tão influentes. Isso ressalta a importância do diagnóstico do aluno acerca da condição de sua turma e de seu professor, pois tais variáveis se mostram fortemente associadas à proficiência.

Mas é notável que a "Sintonia" e a "Expectativa", focos da análise, mostraram-se extremamente significativas, como pôde ser constatado na Tabela 9. A variável "Sintonia" consegue agregar 5,26 pontos, em média, na proficiência em Matemática e 5,49 em Português. Já no caso da "Expectativa", cada unidade de aumento, nessa variável, agrega em média 4,1 pontos na proficiência em Língua Portuguesa e 3,37 em Matemática.

\section{Considerações Finais}

A expectativa do professor, em relação à capacidade do seu aluno alcançar um bom ou um mau desempenho escolar, tem sido apontada como um fator de provável influência no próprio desempenho escolar do aluno. Nesse sentido, a expectativa é, muitas vezes, descrita como sendo responsável por um processo de retroalimentação em que uma boa expectativa amplifica o próprio desempenho e uma má expectativa diminui ainda mais a possibilidade de se ter um bom desempenho. Este estudo mostra, a partir de fortes evidências empíricas, que, em parte, esse ponto de vista está correto, mas que outros fatores podem interferir, notoriamente, determinadas características do professor, apontadas pelos alunos, sobre sua postura em sala de aula.

A expectativa do professor se associa com a sintonia entre o que ele espera para o resultado de todos os alunos de sua turma e o que é observado nos testes. De fato, há professores que exageram na sua expectativa e, por isso, superestimam os resultados de seus alunos, e há aqueles 
Tabela 9. Modelo de regressão linear hierárquico para as proficiências em língua portuguesa e matemática.

\begin{tabular}{|c|c|c|c|c|c|}
\hline \multirow{2}{*}{$\begin{array}{l}\text { Variáveis do } 1^{\circ} \\
\text { Nível }\end{array}$} & \multirow{2}{*}{$\begin{array}{l}\text { Variáveis do } \\
2^{\circ} \text { Nível }\end{array}$} & \multicolumn{2}{|c|}{ Língua Portuguesa } & \multicolumn{2}{|c|}{ Matemática } \\
\hline & & Coeficientes & $p$ & Coeficientes & $\mathrm{p}$ \\
\hline \multirow[t]{16}{*}{ Intercepto } & Intercepto & 225,71 & 0,00 & 235,61 & 0,00 \\
\hline & Interesse e Dedicação do Professor & 2,61 & 0,00 & 3,26 & 0,00 \\
\hline & Barulho e Bagunça em Sala de Aula & $-2,88$ & 0,00 & $-4,44$ & 0,00 \\
\hline & Exigência do Professor & 0,75 & 0,00 & 1,03 & 0,00 \\
\hline & $\begin{array}{l}\text { Falta de Compromisso dos Professores e } \\
\text { Alunos para com a Aula }\end{array}$ & $-3,91$ & 0,00 & $-5,74$ & 0,00 \\
\hline & Compromisso do Professor com o Dever & 0,74 & 0,00 & 1,89 & 0,00 \\
\hline & Percentual de Pretos & $-17,48$ & 0,00 & $-24,40$ & 0,00 \\
\hline & Defasagem Média & $-4,71$ & 0,00 & $-5,46$ & 0,00 \\
\hline & $\begin{array}{l}\text { Percentual de Alunos que Recebem } \\
\text { Bolsa-Família }\end{array}$ & $-36,69$ & 0,00 & $-40,00$ & 0,00 \\
\hline & Falta de Colaboração dos Pais & $-0,53$ & 0,03 & $-0,83$ & 0,00 \\
\hline & Coesão e Trabalho em Equipe & $-0,56$ & 0,03 & $-0,19$ & 0,50 \\
\hline & Percentual de Alunos do Gênero Masculino & $-16,33$ & 0,00 & $-18,81$ & 0,00 \\
\hline & Indisciplina dos Alunos & 0,12 & 0,63 & $-0,26$ & 0,32 \\
\hline & Carência de Materiais e Instalações & $-0,44$ & 0,07 & $-0,34$ & 0,21 \\
\hline & Expectativa & 4,16 & 0,00 & 4,35 & 0,00 \\
\hline & Sintonia & 5,19 & 0,00 & 6,38 & 0,00 \\
\hline $\begin{array}{l}\text { Gênero } \\
\text { Masculino }\end{array}$ & Intercepto & $-6,54$ & 0,00 & 2,32 & 0,00 \\
\hline Cor Preta & Intercepto & $-4,75$ & 0,00 & $-6,94$ & 0,00 \\
\hline $\begin{array}{l}\text { Defasagem do } \\
\text { Aluno }\end{array}$ & Intercepto & $-3,91$ & 0,00 & $-4,53$ & 0,00 \\
\hline $\begin{array}{l}\text { Receber Bolsa- } \\
\text { Família }\end{array}$ & Intercepto & $-5,79$ & 0,00 & $-5,86$ & 0,00 \\
\hline
\end{tabular}

que são demasiadamente moderados com relação a sua expectativa e, por isso, subestimam os resultados. Muito provavelmente, em parte, a sintonia entre o desempenho esperado e o observado é um reflexo de um diagnóstico baseado em algum conhecimento das capacidades cognitivas dos alunos, mas pode ser também, como demonstrado no estudo, uma construção baseada nas características socioeconômicas dos alunos. Podemos, então, sugerir que, de certa forma, o diagnóstico do professor e, consequentemente, sua expectativa são influenciados por estereótipos. De fato, mesmo controlando-se pela sintonia e pelas proficiências dos alunos, a expectativa do professor é modulada pelo perfil de sua turma. Variáveis como o "Percentual de Alunos do Gênero Masculino", 
o "Percentual de Pretos" e o "Percentual de Alunos que Recebe Bolsa-Família", e algumas atitudes do professor frente às condições escolares, como a "Carência de Materiais e Instalações", a "Falta de Colaboração dos Pais" e a "Coesão e Trabalho em Equipe" estão associadas a uma menor expectativa, mesmo quando se considera alunos com mesmas habilidades cognitivas.

Por outro lado, o fato é que a expectativa do professor continua tendo efeito positivo sobre a proficiência, mesmo quando se controlam os efeitos de todas essas variáveis. Como foi visto, o efeito líquido da expectativa é tal que agrega em média 4,1 pontos na proficiência em Língua Portuguesa e 3,37 em Matemática, para cada unidade a mais na escala da expectativa. Esse fato sugere que a expectativa tem efeito próprio.

Também parece ser muito importante, na explicação da proficiência, o conhecimento pelo professor do nível de habilidades da turma. Isso fica sugerido pelo fato de a variável sintonia ter um efeito líquido positivo sobre a proficiência, controlando-se todos os demais fatores. A variável "Sintonia" consegue agregar 5,26 pontos em média na proficiência dos alunos em Matemática e 5,49 em Português.

Por uma série de razões sociais e econômicas, verificase que alunos do gênero masculino, de cor preta e baixa condição socioeconômica, de fato, tendem a apresentar um desempenho inferior. Porém, o que este estudo mostra é que se o professor apresenta uma boa expectativa do desempenho dos seus alunos, maiores proficiências são observadas para todos os alunos, independentemente das características socioeconômicas. Por outro lado, o conhecimento da capacidade cognitiva dos alunos também está associado a maiores proficiências. Isso sugere ser importante que o professor crie estratégias para buscar conhecer sua turma como meio de produzir uma ação mais efetiva frente às necessidades de seus alunos.

\section{Referências}

Alvidrez, J., \& Weinstein, R. S. (1999). Early teacher perceptions and later student academic achievement. Journal of Education Psychology, 91, 731-746.
Bonamino, A. M. C. (2002). Tempos de avaliação educacional. $O$ SAEB, seus agentes, referência e tendências. Rio de Janeiro: Quartet.

Clifford, M. M., \& Walster, E. (1973). The effect of physical attractiveness on teacher expectations. Sociology of Education, $46,248-258$.

Franco, C., Ortigão, M. I. R., Albernaz, A., Bonamino, A. M. C., Aguiar, G., Alves, F., \& Satyro, N. (2007). Qualidade e equidade em educação: reconsiderando o significado de "fatores intra-escolares". Ensaio. Avaliação e Políticas Públicas em Educação, 15, 277-297.

Johnson, R. A., \& Wichern, D. W. (1992). Applied multivariate statistical analysis. Englewood Cliffs: Prentice Hall.

Klein, R. (1997). Indicadores educacionais e disparidades regionais e socioeconômicas no Brasil. Em H. Bomeny (Org.), Avaliação e determinação de padrões na educação latinoamericana (pp. 47-86). Rio de Janeiro: Fundação Getúlio Vargas.

Lee, V. L. (2001). What are multilevel questions, and how might we explore them with quantitative methods? Estudos em Avaliação Educacional, 24, 31 - 68.

Lord, F., (1980). Applications of item response theory to practical testing problems. Hillsdale: Lawrence Erlbaum.

Penna Firme, T. (1982). Avaliação do professor. Tecnologia Educacional, ABT, 48, 10-11.

Rosenthal, R., \& Jacobson, L. (1968). Pygmalion in the classroom: Teacher expectation and pupil's intellectual development. New York: Holt, Rhinehat \& Winston.

Soares, T. M. (2003). Influência do professor e do ambiente em sala de aula sobre a proficiência alcançada pelos alunos avaliados no SIMAVE-2002. Estudos em Avaliação Educacional, 28, 103-123.

Soares, T. M. (2005). Modelo de três níveis hierárquicos para a proficiência dos alunos de $4^{\mathrm{a}}$ série avaliados no teste de Língua Portuguesa do SIMAVE/PROEB-2002. Revista Brasileira de Educação, 29, 73-87. 